\section{Women Rising to the Top: The Tipping Point for the ASNR}

\author{
(D)C.C. Meltzer, DP.C. Sanelli, M.B. Hepp, and (D).A. Bello
}

$\mathrm{L}^{\mathrm{s}}$ ike many leading professional academic societies, the American Society of Neuroradiology (ASNR) has enjoyed a rich history of visionary leadership. Yet, from its birth in 1962 through 2009, only 2 of the 46 ASNR Presidents were women (with 17 years separating their appointments). The striking change in demographics of the ASNR leadership during the past decade appears to demonstrate a clear tipping point. In this most recent decade, 5 of the 9 Presidents have been women (Figure). Given the establishment of the Women in Neuroradiology Leadership Award in 2010 and other efforts, ASNR stands out as a national radiology society that has reached a tipping point from which lessons may be learned.

The field of radiology has a long history of being male-dominated. Even as women have achieved equity in medical schools in recent years, radiology remains characterized by one of the lowest proportions of women among medical specialties. ${ }^{1}$ With just more than one-quarter of radiologists being women, neuroradiologists especially lack female colleagues; the current ASNR membership includes less than 18\% women (ASNR membership records 2018).

The advancement of women into leadership positions has been slow across medicine, with women representing a paucity of chairs, deans, and practice and society leaders. ${ }^{1}$ Radiology is no exception. Thus, it was not until 2018 that the American College of Radiology (ACR) named its first female chair of the Board of Chancellors in its 95-year history. Recently, Ahmadi et $\mathrm{al}^{2}$ reported a strong correlation between gender and academic leadership positions among neuroradiologists, with $87.5 \%$ of leadership ranks occupied by men.

\section{Differential Support for Professional Advancement}

Research accomplishments often serve as a gateway to professional advancement. There is mounting evidence that male physicians and scientists in science, technology, engineering and mathematic fields enjoy greater scholarship opportunities impacting consequential publications, ${ }^{2,3}$ research grants, ${ }^{4}$ awards and honors, and leadership opportunities relative to their female counterparts. Considering the grants and awards bestowed by the ASNR and the Foundation of the ASNR, the gender imbalance is evident (Table). Yet for some awards, there have been improvements in the past decade. For example, from 1992 to 2009, only 4 of the 38 Cornelius G. Dyke Awards (10.5\%) were received by women; from 2010 to 2018, three of the 8 awards $(37.5 \%)$ went to female applicants. Not unexpectedly, gender imbalance was greatest for the senior honorary awards such as the Gold Medal (bestowed to only 1 woman of 33 awardees [3.0\%]) and Outstanding Research Contributions (bestowed to only 1 woman of 14 awardees $[7.1 \%])$.

http://dx.doi.org/10.3174/ajnr.A5893
Even in the most recent decade in which women were awarded more grants and honors than previously, the rates of awards still lagged behind the proportion of female applicants. Since the inception of the ASNR Comparative Effectiveness Awards in 2011, women have made up $41.3 \%$ of applicants yet were only $14.3 \%$ of awardees. Similarly, for the Research Scientist Award, 36.7\% of applicants versus $12.5 \%$ of awardees were women.

\section{Contributors to the Tipping Point}

Tipping points in societal norms are an interesting phenomenon. Recent cultural examples that have received much attention are the rapid spread of public resistance to workplace harassment and mass gun violence as embodied by \#MeToo and \#NeverAgain, respectively. Centola et $\mathrm{al}^{5}$ argue that tipping points in social convention may be explained by the theory of critical mass as posited by the evolutionary game theory. When a committed minority reaches a certain size, which they showed to be approximately $25 \%$ through experimental constructs, the social system crosses a tipping point at which a rapid change in attitude and behaviors favor the minority view.

Kim and Mauborgne ${ }^{6}$ framed tipping point leadership as a change management that requires overcoming 4 types of hurdles: cognitive, political, resource, and motivational. This construct is applicable to examining factors that potentially contributed to the leadership tipping point of the ASNR.

Much has been written about cognitive barriers to the advancement of women's careers. Our implicit biases, particularly in male-dominated professions and organizations, reinforce our expectation that men will serve as leaders and women will occupy support roles. ${ }^{7}$ The persistence of these deeply embedded but rarely spoken barriers is sometimes referred to as second-generation bias. In such a climate, women who express leadership interests may be criticized rather than supported. ${ }^{8}$ Yet as women take on leadership positions and serve as counter-stereotype exemplars and role models for other women, cognitive barriers can be eroded with time.

Political hurdles may also be ingrained and not well-recognized. Coalitions of like-thinking individuals may exert undue influence on the strategy and direction of an organization and become largely responsible for the distribution of formal and informal positions of power. ${ }^{9}$ This dynamic can be further solidified by organizational structures and by-laws that favor those in key positions assuming additional roles of power. One example might be the structure of the ASNR in which the President-Elect serves as the Chair of the Nominating Committee, a position that oversees the nomination process for the incoming leadership positions.

Resources that have been shown to support the professional advancement of women include mentorship and leadership development programs. In 2010, as the ASNR neared its 50th anniversary, the idea of an ASNR-sponsored award for promising midcareer female neuroradiologists began to develop. The intent was to support such women both through national recognition of their leadership promise and leadership skill-building. The following year, a call for nominations for the Women in Neuroradi- 


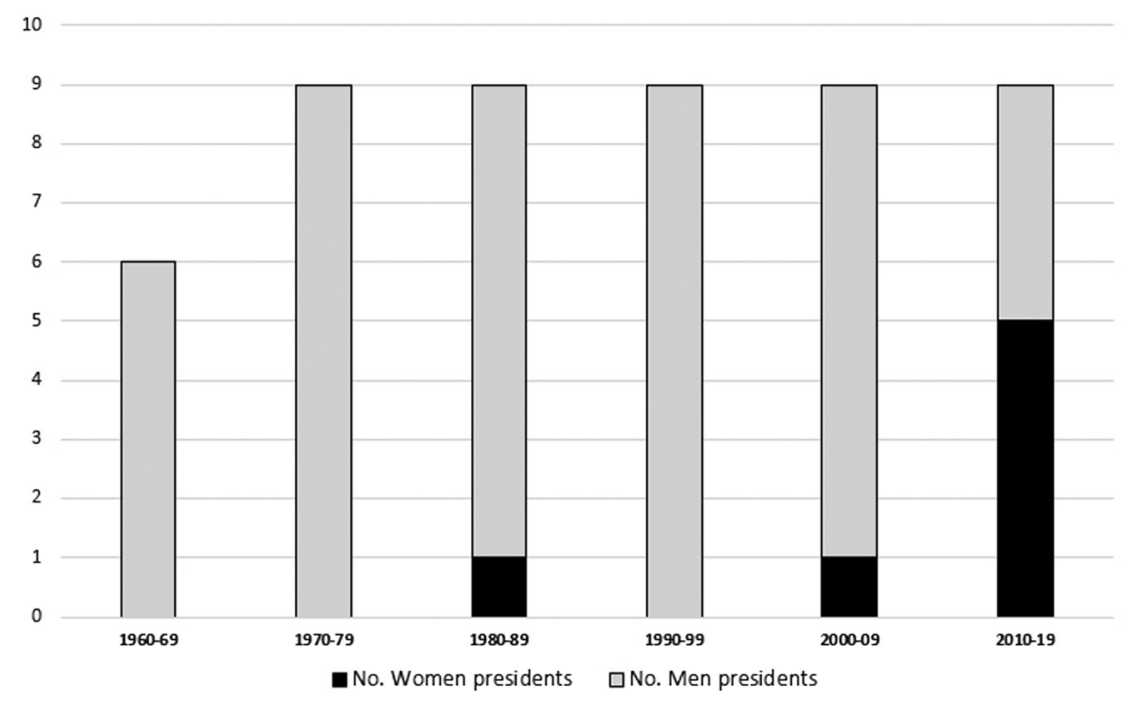

FIGURE. The number of male-versus-female ASNR Presidents by decade (note the first President was appointed in 1962 with an initial term of 2 years).

Gender balance of ASNR awards and grants

\begin{tabular}{|c|c|c|c|c|c|}
\hline \multirow[b]{2}{*}{ Award Name/Type } & \multirow[b]{2}{*}{$\begin{array}{c}\text { Years } \\
\text { Awarded }\end{array}$} & \multicolumn{2}{|c|}{ All Years } & \multicolumn{2}{|c|}{ Past Decade (2010-2018) } \\
\hline & & $\begin{array}{c}\text { No. of } \\
\text { Awardees (M/F) }\end{array}$ & $\begin{array}{l}\text { \% Female } \\
\text { Awardees }\end{array}$ & $\begin{array}{c}\text { No. of } \\
\text { Awardees (M/F) }\end{array}$ & $\begin{array}{l}\text { \% Female } \\
\text { Awardees }\end{array}$ \\
\hline Cornelius G. Dyke Award//honor ${ }^{\mathrm{a}}$ & $1992-2018^{b}$ & $38(34: 4)$ & 10.5 & $8(5: 3)$ & 37.5 \\
\hline Scholar Award/grant & $1999-2018^{c}$ & $24(14: 10)$ & 41.7 & $12(8: 4)$ & 33.3 \\
\hline Gold Medal/honor & 1995-2018 & $33(32: 1)$ & 3.0 & $10(10: 0)$ & 0.0 \\
\hline Outstanding Contributions/honor & $2004-2018^{d}$ & $14(13: 1)$ & 7.1 & $9(8: 1)$ & 11.1 \\
\hline Research Scientist Award/grant & 2011-2018 & $8(7: 1)$ & 12.5 & $8(7: 1)$ & 12.5 \\
\hline Comparative Effectiveness/grant ${ }^{\mathrm{e}}$ & 2011-2018 & $7(6: 1)$ & 14.3 & $7(6: 1)$ & 14.3 \\
\hline
\end{tabular}

${ }^{a}$ Established to honor Cornelius G. Dyke, one of the pioneers in neuroradiology, given to an assistant professor, fellow, or resident for excellence in original research.

' No award in 1976, 1980, 1983, 1985, 1987, 1998, 2001, 2003, 2005, 2008, and 2011.

c Two awards per year in 2010, 2017, and 2018.

dNo award in 2006.

e No award in 2013.

ology Leadership Award was announced in partnership with the ACR and the American Association for Women Radiologists, and the first award was bestowed in $2012 .{ }^{10}$ The annual awardees have been celebrated by all 3 organizations, and funding has been provided for the recipient to attend the ACR Radiology Leadership Institute Summit. Two of the 7 awardees to date have ascended to officer positions in the ASNR, including the current President, as well as attaining leadership roles in other professional organizations.

While the motivational forces responsible for an organizational tipping point are the most difficult to evaluate and quantify, it is likely that a critical mass of engaged women and male champions is largely responsible for the momentum achieved. While the leadership structure of the ASNR had been overwhelmingly male for most of its history, in this most recent decade women made up an average of nearly one-third of the executive committee (compared with an average of $12 \%$ during the prior decade). As a pipeline to the presidency, the appointment of increasing numbers of women to this body is further evidence of sustained change. While progress is to be celebrated and we believe the momentum for positive change is considerable, there is more work to do. Since its first issue in 1980, the premier journal in the field, the American Journal of Neuroradiology, has never had a female editor at its helm.

\section{Summary}

The ASNR is the premier professional society for neuroradiology, a field that persists in attracting and training a minority of women. While there has been only slow progress in the number of women entering radiology overall and particularly neuroradiology, in the past decade the ASNR has demonstrated dramatic positive change in the gender diversity of its leadership. Between 1962 and 2009, only 2 of the 46 ASNR Presidents were women, yet in this most recent decade, more than half of the Presidents appointed have been women. In this editorial, we attribute this tipping point change to a variety of factors.

Disclosures: Carolyn C. Meltzer—UNRELATED: Board Membership: GE-Association of University Radiologists Scientific Board, Comments: reimbursement from the Association of University Radiologists for travel to meetings; Consultancy: Wake Forest Health, University of Tennessee Medical Center, University of Massachusetts, University of Pennsylvania, Northwestern University; Employment: Emory University; Expert Testimony: Attorney General Nashville, Tennessee; Floyd Pflueger \& Ringer, Seattle. Mary Beth Hepp—UNRELATED: Employment: ASNR, Comments: I am the Executive Director of the ASNR and have access to statistical data related to this article. Jacqueline A. Bello-OTHER RELATIONSHIPS: I am a recent past female President.

\section{REFERENCES}

1. AAMC Report: The State of Women in Academic Medicine: The Pipeline and Pathways to Leadership, 2013-2014. https://members. aamc.org/eweb/upload/The\%20State\%20of\%20Women $\% 20 \mathrm{in} \%$ 
20Academic\%20Medicine\%202013-2014\%20FINAL.pdf. Accessed November 1, 2018

2. Ahmadi M, Khurshid K, Sanelli PC, et al. Influences for gender disparity in academic neuroradiology. AJNR Am J Neuroradiol 2018;39: 18-23 CrossRef Medline

3. Shen YA, Webster JM, Shoda Y, et al. Persistent underrepresentation of women's science in high-profile journals. bioRxiv $2018 \mathrm{https}: / /$ www.biorxiv.org/content/early/2018/03/08/275362. Accessed November 1,2018

4. Magua $\mathrm{W}, \mathrm{Zhu} \mathrm{X}$, Bhattacharya A, et al. Are female applicants disadvantaged in National Institutes of Health peer review? Combining algorithmic text mining and qualitative methods to detect evaluative differences in R01 reviewers' critiques. $J$ Womens Health (Larchmt) 2017;26:560-70 CrossRef Medline

5. Centola D, Becker J, Brackbill D, et al. Experimental evidence for tipping points in social convention. Science 2018;360:1116-19 CrossRef Medline
6. Kim WC, Mauborgne R. Tipping Point Leadership. Harvard Business Review, April 2003. https://hbr.org/2003/04/tipping-point-leadership. Accessed June 29, 2018

7. Meltzer CC. Women leaders: myths and challenges. JAm Coll Radiol 2018. Jul 25. [Epub ahead of print] CrossRef Medline

8. Ibarra H, Ely RJ, Kolb DM. Women Rising: The Unseen Barriers. Harvard Business Review September 2013. https://hbr.org/2013/09/ women-rising-the-unseen-barriers. Accessed June 2, 2018

9. Zaleznik A. Power and Politics in Organizational Life. Harvard Business Review, May 1970. https://hbr.org/1970/05/power-and-politicsin-organizational-life. Accessed September 2, 2018

10. Meltzer CC. Three radiology societies come together to sponsor Women in Neuroradiology Leadership Award. AJNR Am J Neuroradiol Blog. February 3, 2014. http://www.ajnrblog.org/2014/ 02/03/three-radiology-societies-come-together-sponsor-womenneuroradiology-leadership-award. Accessed September 2, 2018 